\title{
An Autobiographical Analysis on Formation of Personalized English Teaching Style
}

\author{
Wang Wenqing \\ Zhejiang University, Hangzhou, China; \\ Zunyi Teaching Science Research Society, Zunyi, China
}

\begin{abstract}
Basing on a series of surveys on teacher development, teaching style formation, and personalized teaching style analysis, the belief that the formation of personalized teaching style is essential to the development on diversification of educational ideology. Hence, diversity and personality of educational ideology shall contribute as a great leap to the flourishment of teaching methodology. This study is a narrative observation on a Chinese English-language teacher's teaching career development and a scientific perspective on her formation of personalized teaching style. Analysis on formation of personalized English teaching style of the Chinese English-language teacher will be proceeded from three aspects: (a) the starter: bud insight of educational ideology from the reviews of family, school, and society backgrounds; (b) the touches: educational notion formation in teaching practice to individuals and classes in process; and (c) the analysis: analysis on formation of personalized English teaching style.
\end{abstract}

Keywords: personalized, autobiographical, formation, teaching style

\section{Introduction}

Diversification (Himmelspach, 2009) contributes as a leaping development to ideology as well as strategies in human culture history. With ideologists like Confucius (771BC-479BC), Lao Tzu (571BC-471BC), Mencius (372BC-289BC), and many other hundreds of ideologists consisting of Contending of Hundred Schools of Thought in the Spring and Autumn Period in China (770BC-221BC), and also with ideologists Dante Alighieri (1265-1321), Leonardo da Vinci (1452-1519), William Shakespeare (1564-1616), and many other hundreds of the archetypal Renaissance men in Europe in Renaissance (1400AD-1700AD), great times spark with irreplaceable merits in human culture history. Its diversification in ideology will surely contribute as a great leap in flourishing personalized styles especially on the influence of teaching styles.

Basing on a series of surveys on teacher development, teaching style (Murtazina \& Vendelinb, 2012) formation, and personalized teaching style analysis, the autobiographical analysis on the teaching style of the English teacher Wang Wenqing exhibits that the inevitable impacts on the formation of her personalized teaching style lies in the diversification of formation of her educational ideology through personalized experiences. Hence, diversity and personality of educational ideology shall contribute as a great leap to the flourishment of teaching methodology.

Wang Wenqing, M.Ed., associate professor, Foreign Language Institute, Zhejiang University; Zunyi Teaching Science Research Society. 
This study is a narrative observation on a Chinese English-language teacher's teaching career development and a scientific perspective on her personalized teaching style formation. The formation of a positive teaching style for every teacher is to reflect much upon his/her own personalized teaching style process, therefore, the refection enhances the positive adaptation and formation of lifelong comprehension of English teaching.

\section{Case Study of Wang Wenqing}

This study adopts the case study (Ding, 2012) design. The Chinese English-language teacher, Wang Wenqing, is an experienced teacher of 16 years of teaching experience for primary, junior, senior, and college students, as well as a training teacher, class teacher, school director, and municipal teaching researcher. Her 38 years of life is bounded with English teaching, which is a part of her life. She once learned in Zunyi Normal College, Beijing Normal University, Zhejiang University, and Reading University in the U.K.. Her three-time national first prize in English teachers' profession competition and her practical, distinguished achievement in teaching English to more than thousands of senior high students enable her municipal excellence, provincial top-10 youth, national honored English teaching celebrity, etc.. More than thousands of primary, junior, senior, and college school teachers observe her teaching and were trained by her as well. Some digests from her Website are shown in Figures 1, 2, and 3 (Retrieved from http://user.qzone.qq.com/1423226912/):

\section{好友印象}

阳光天使最好的老师和姐姐我最尊敬的老师

Figure 1. Impression of Wang Wenqing from her friends.

Translation:

A sunny angel; the best teacher and sister; and the most honored teacher.

\begin{tabular}{|c|c|}
\hline \multirow[t]{3}{*}{ 粠 } & 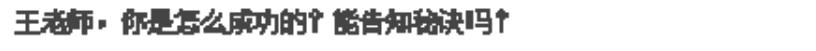 \\
\hline & 2013-08-07 11:35 回可 渼礼 \\
\hline & 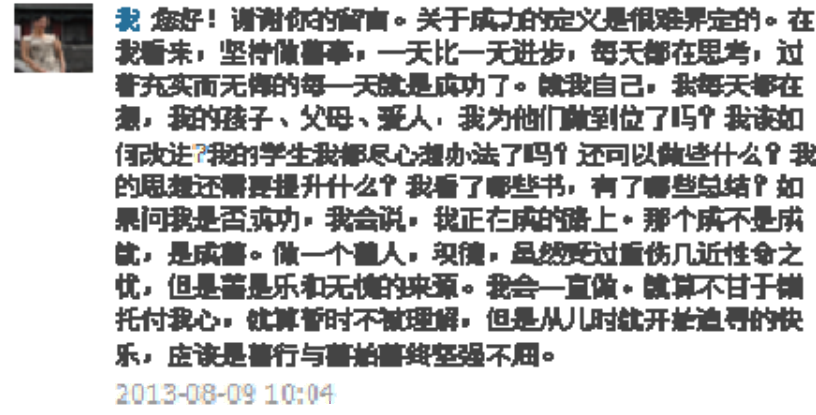 \\
\hline
\end{tabular}

Figure 2. Wang Wenqing's definition of success.

Translation:

A student: Ms. Wang, how have you being successful? Can you tell the key to success?

Wang Wenqing: Hi! Thank you. The definition of success is still difficult to regulate a criterion. From my viewpoint, success means to persist in doing good deeds, to improve day by day, to ponder day after day, and to live a fulfilled and 
busy life without regrets every day. As for myself, I am thinking of what I did for my kid, my parents, and my spouse. Have I fulfilled my responsibility? How should I adapt and improve? Have I tried my best to teach? Is there anything more I can do for them? What should be enhanced in ideology? What books have I read? Any thing needs to summarize? If you ask me whether I am successful, I will tell you that I am on the way to. I am trying to be a man of goodness, but not of certain achievements; to be a man of goodness and to do much good deeds. Though we may experience terrible wounds that endanger life, goodness can be the origin of happiness and non-regret. I will persist in doing what I pursuit since I was a child — to do good deeds from start to end indomitably, regardless of the hardships and misunderstandings.

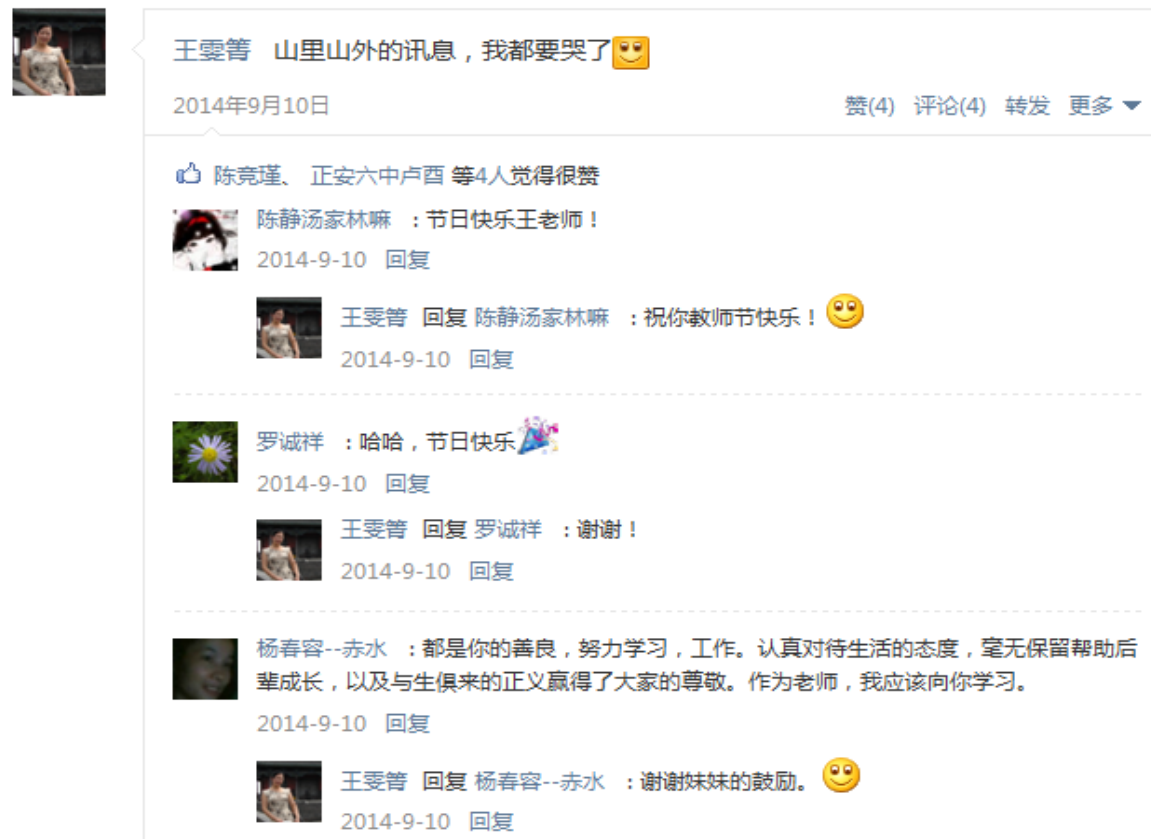

Figure 3. Wang Wenqing's sharing of messages on her personal website.

Translation:

Wang Wenqing: I am moved on seeing the messages from in and out of the mountain.

A student: Happy Teachers' Day, Ms. Wang.

A teacher: Your goodness, diligence, and attitude towards life and work, assistance for later followers wholeheartedly, and the born sense of righteousness reward you with respect. We teachers should learn from you.

\section{Analysis on Formation of Personalized English Teaching Style of Wang Wenqing}

\section{The Starter: Schooling Life's Bud Insight of Educational Ideology From the Reviews of Family, School,} and Society

Educational ideology is abstract but an engine with flowing power to the formation of personalized style in action. Education or teaching is greatly influenced by family, school, and society. The three factors interact on the learner and the learner determines its aim and direction with his/her stable style of actions.

Family critical incidence that impresses educational ideology. Family critical incidents (FitzGerald, Seale, Kerins, \& McElvaney, 2008) have a series of stable impact on Wang Wenqing's career choice to be an influential teacher and on her character of being encouraging, persistent, and devoted.

Incident 1: Challenging. Wang Wenqing's hometown residence is a two-floored wood house with wooden stairways. Her busy parents left her cared by her grandparents. The time she learned to climb the steep 
stairs impressed her for a life when she challenged the steep stairs and received encouragement from her grandfather and he showed great admiration to her action by every bit of her attempting in reciting ancient poems, retelling folk stories, rhyming children chants, calculating the sums, finishing the rice drops, admitting her wrongdoings, etc.. The challenge taken physically and mentally with encouragement and admiration fill her up with confidence and bravery in action.

Incident 2: Perseverance. On a burning sunny autumn afternoon day, Wang Wenqing followed her grandmother picking the fresh ripe-red chilies when she was just six years old. Sweater face and chilly-hot hands urged her asking grandmother for quitting while she just heard the words kept in her memory for life. "Just keep on what you are doing and you will surely find you can do it. Once start, just finish it". The perseverance is keeping her up in the way of working on teaching research.

Incident 3: Goodness. Wang Wenqing's grandmother is a real life philosopher for her. The childhood books on Western and Eastern philosophy are helping to seek an answer to sense of happiness and thought, like in the stories about Diogenes (?-320BC) and Alexander the Great (356BC-323BC) titled The Burglar and the Emperor and myth of Kuafu Running After the Sun. Her grandmother tells her:

There exists no God or ghost in the world. Doing good, God sees it. Doing bad, the ghost lives in your heart. You yourself is the God to support yourself, but rewarding and returning is what I believe. Doing good deeds will pay you with good for you and your descendants.

Schooling critical incidence that impresses educational ideology. The impressive and truly-felt teaching styles exist in teachers' own life with their own experience for years. They can excavate the styles to imitate. Patience, sincerity, democracy, encouragement, dignity, wisdom, and many are factors that teachers should bear in mind in their own teaching career.

Teacher 1: Wang Yuanheng (Abecedarian teacher). Wang Yuanheng was a grey-haired elegant lady around 60 when she taught Wang Wenqing in primary school from Grades 1 to 3 since 1983. The first year of schooling is full of stories of struggling, surprising, and excitement. The only thing her students never give up is continuously attempting. She assigned weekly-monitor responsible for classroom cleaning and homework collecting and handing, etc.. Wang Wenqing remembered clearly the week she did the monitor and got the teacher's praise that she knocked at her door politely with three gentle knocks. She urged her students not to give up in attempting rope jumping, square-boxes jumping, bamboo pole climbing, etc.. In the 3rd grade, when most of her students failed in studying and becoming noisy in classroom learning, she informed the parents and asked all the class to stay for another half an hour after school for a month to practice military training like “Attention”, “At ease”, "Halt”, “(Turn) Left”, “(March) Front”, “(Turn) Right”, “(Turn) Back”, "Marching”, etc.. The students are doing it for fun at first, and then they are doing it to verify their enthusiasm, perseverance, and unity in learning, especially for math learning. The teacher once mysteriously asked the students to stay in classroom and went shopping to get a small bag of dried grapes for them to taste after they just learned the lesson Grape Valley in Turpan.

Her wisdom, patience, strictness, and consideration are her true love to students, and thus, impact Wang Wenqing's lifelong educational ideology.

Teacher 2: Wang Tianfu (Junior class teacher). Under Wang Tianfu's guidance of teaching, his students enjoyed three years (six times) of outing picnic organized by the class committee. He once mysteriously assigned a task to two students in class of uniting all small groups of classmates together with activities. More 
than 20 years passed, the class get-together would always attract almost everyone of the 60 students to enjoy the gathering. He did nothing in class management but he observes and knows clearly all the situation. He does not speak standard Mandarin and his pet phrase is "It only can be felt but not be expressed". But his teaching is the one his students all enjoy when they would be praised and admired by him or other classmates for their outstanding explanations and excellent Mandarin performance.

His democracy encourages students' creativity and enthusiasm in learning. Their desire for knowledge and organizing activities has been flamed to burn for a long time in life.

Teacher 3: Ran Yang (Abecedarian English teacher in junior school). Ran Yang is a fairy lady with noble dignity and pronunciation of standard English with logical teaching demonstrations. Her deliberate fashionable clothes decoration makes her a beauty and the English learning is becoming a way of learning about beauty and nobleness. Every lesson is designed in a way of logical presentation. An interesting start, a challenging and rich procedure, a practice for comprehension checking, and a summary for all learned in the lesson or in a period of time comprise all she planned for her students to master. She treats the diligent students warmly and the lazy bones coldly while she was loved by both as the students understand her intention and expectation. She is a friend and teacher.

She is so unique and is worthy to be admired for her knowledge and integrated talents in teaching English. She is leading a life-way of teaching and she is leading the students to be noble man in life with dignity.

Society critical incidence that impresses educational ideology. Zunyi is a historical city with diversity historical culture testimony. Some national educators include Yin Zhen (79-162) in Donghan Dynasty; Ran Jin (?-1253) and Ran Pu (?-1260) Brothers in Southern Song Dynasty; Zheng Zhen (1806-1864), Mo Youzhi (1811-1871), and Li Shuchang (183701896) in Qing Dynasty; Liu Zunyi (1944-now), former president of Hongkong University; and Zhou Lin (1912-1997), former Vice Minister of Education. People in Zunyi are not only hardworking for producing the national wine Maotai, but also emphasize a lot on education. Many celebrities in Zhejiang University were studying or working in Zunyi in the time of Anti-Japanese War when Zhejiang University moved to Zunyi by President Zhu Kezhen.

Wang Wenqing was and is now a student in a university and she works as a municipal English teaching researcher. She is working as a translator and interpreter of Zunyi Hailongtun Tusi Fortress to be voted for 2015 World Culture Heritage. Her desire of doing more on verified teaching style to contribute in education diversity emerged and kept in her mind and she is doing it as her key research field at present.

\section{The Touches: Educational Notion Formation in Teaching Practice to Individuals and Classes in Process}

The years in Zunyi Normal College and the first year in Zunyi Aerospace Senior High School from 1995-1999 are Wang Wenqing's fresh touch of teaching practice.

Fieldwork 1: Individual tutoring. The year Wang Wenqing was enrolled in Zunyi Normal College in 1995 is a gloomy one, for she was deeply disappointed with her performance and sought for a breakthrough. She accepted any offer for tutoring. The first one is for a 10 -year old boy whose father is professor with a doctor degree and the challenge is his recognition in her work. The first time they met is an English conversation and what she prepared is a strictly corrected and tensely practiced English pronunciation. She also read books on children psychology to meet any incidence in his learning procedure. The weekends of her first year in college are busily scheduled with individual English teaching for a primary student learning New Concept English, a Junior 3 student preparing for senior high school entrance exam, a Senior 3 student preparing for College Exam, and an adult learning for further education. Her rest and dinner are on the bus with 
a tiring body and a determination to some breakthroughs. In the same year, she passed College English Test Band 4. Hardship rewards her with enough income for life and confidence in English for teaching students.

Enough preparation and determination to overcome difficulty is necessary and can be rewarding to the devotees.

Fieldwork 2: Classroom teaching attempting. In the summer of 1996, some parents invited Wang Wenqing to give lessons to their children in Junior 1. They organized a class about 40 and she taught them primary school English for revision of Junior 1 and prepare them for Junior 2. She found that their interest in learning English is the barrier in learning and some of them were in a dilemma of giving up or continually trying and they were expecting some strategies to regain the confidence and interest in learning. What she adapted in her teaching are two things: One is to help the students understand the usage of learning English by demonstrating its importance and reality usage and practical using of English, and the other is to help the students find the interest of learning by presenting challenging tasks and renovating their confidence in learning.

Knowing the importance of leaning English and making the interesting learning process sustainable are essential to younger learners.

From the autumn term of 1996, Wang Wenqing was invited by a primary school to give lessons on weekends. That was really a tough job with more than 50 noisy kids. They would not understand the importance and usage of learning English. They were naughty and noisy if you cannot communicate effectively with them. They need to be concerned and they are longing for a chance to show themselves. She read many Oxford series of books for language teachers. There are many games and activities. She read different English learning books for starters, like Family Album USA, Victor English, Huangbo Children English, TPR English, New Concept English, and some years later, Disney English and Dashan Canadian English. By collecting and practicing the learning activities, by reading and observing children's psychological behaviors, and by organizing students doing tasks in a dynamic and statically way of classroom flowing, she utilized the kids' naughty and noisy to a powerful learning effect, and what she rewarded was becoming a municipal teachers' trainer for primary schools.

Reading classical books for applying activities and English classroom teaching with a rhyme in a dynamic and statically way make the efficiency of learning. It led to her two months teaching practice in Suiyang Middle School a highly successful experience with the students and some of the students are setting their dreams to learn excellently as her. Some of the students are still keeping in touch with her.

The year of 1998 saw her first year in a provincial key senior high school as a senior school English teacher. The pressure from parents, colleagues, and students notifies her of studying further and treats her work seriously. The first lesson she presented to her students shocked them her pronunciation and the mid-term and end-term achievement persuaded her colleagues. Her first public lesson to English teachers in Aerospace Basement (a national enterprise with provincial level) is a propaganda of new teaching styles to learn from. They say, using English to teach English is wonderfully performed, the enthusiastic teaching environment is touching, and students' active response is amazing.

Wang Wenqing realized that a systematic style of teaching should be found to make her teaching concerning every learner. She also realized that she should study more cases and learn from the experienced teachers. The College Exam can be a proof of what she is learning and doing. Her bud insight is just a bud. The bud should experience different kinds of situations with storms, sunshine, wind, and earthquakes. Action 
speaks loudly.

In years of 1998-2000, Wang Wenqing experienced leaping development in English teaching with the help of her master teacher ( $\mathrm{Shi} \mathrm{Fu}$ ) as an apprentice of him. His name is Yan Yong. He is one of the best teachers in Zunyi and he is open-minded to transmit all his understanding in English teaching to her. She followed him to his class for a year and more and she discussed with him on any problem she encountered in teaching English. His guidance is critical to her perfection in teaching.

A modest attitude and a good master teacher are important in teaching development. People cannot see themselves clearly but their master or best friends can give them suggestions unselfishly .

Fieldwork 3: Teacher training. Since 1996, Wang Wenqing worked as a primary school English trainer for some schools. In 1999, she was invited to train municipal primary school teachers. Since then, she trained undergraduates in Zunyi Normal University, and teachers from primary school, junior school, and senior school every year till now.

What she taught before are mainly on classroom teaching methodology, teaching and learning strategies, testing and assigning paper method and analysis, carrying out teaching project work, etc..

The achievement she cherishes is the wisdom of every teacher she found in their work. Leading them to discover and reflect on their own teaching and forming a personalized effective style are her aim of working in this period.

\section{English Teaching Development Based on Analysis}

Analysis 1: Student. Every student is individually characterized from different families with different impacts on his/her thought ideology. Any factor that is crucial to his/her leap in English language understanding can never be predicted.

Psychological need analysis, management of students' learning, analysis of students' language proficiency are the preparation before her class.

Analysis 2: Teaching aim. A clear aim is for teachers to follow and for the students to check what they learnt. She grouped aim into three categories and immerge them in every lesson. The first one is about emotion and culture. The second one is about knowledge and proficiency. The third one is about strategies. All together is just one aim. That is, learning ... knowledge and be proficiency in ... by the ... strategy, forming a positive ... emotion on ... culture.

A clear aim is the only efficient means towards future. It should be set and designed carefully.

Analysis 3: Teaching materials. Textbook is one of the teaching materials. More materials should be collected, grouped, reflected, and selected before presentation. Teaching materials include: background on culture, emotional reflection on real life, knowledge relation on language, proficiency practice and test, several competitive and challenging learning or consolidation activities, etc..

Teaching material preparation is more than a task for teaching English and it can be a sustainable way for teacher development in lifelong learning. It worthy to be done everyday.

Analysis 4: Teaching effectiveness. The testimony of teaching effectiveness is advocated to enhance the confidence of learners and the teacher. People need not to be the best, but they must be a better one than the one in yesterday. Teachers should analyze the present language proficiency and regulate a baseline of every student. The teaching effectiveness will be realized by scientific analysis and practical teaching action after continuous reflection and improvement. Teacher development is not done in one day, but a lifelong learning procedure. 


\section{Conclusion}

Researching on personalized English teaching style is a long way to gain an awareness of the teacher herself/himself in ideology and action. Putting ideology concerning student learning into practice and improving teaching strategies cautiously are necessary requirements to be a personalized teacher. It is the love to students that attracts teachers to enhance themselves to be better. More studies basing on data and facts around learning assessment shall be further practiced. Personalization is a process of bitterness to crack the old ones and makes a new time better. Teaching with positive attitude, enthusiastic atmosphere, and philosophical pondering on English teaching with a clear aim and logical presentation in challenging and questioning activities is Wang Wenqing's personalized English teaching style. In the future, she has more steps to take, more books to read, and more styles to exploit.

\section{References}

Brown, J. S., Collins, A., \& Duguid, P. (1989). Situated cognition and the culture of learning. Educational Researcher, 18(1), $32-42$.

Ding, Y. H. (2012). A case study of teaching style formation from the perspective of an ordinary teacher in university. Journal of Jixi University, 4-5.

FitzGerald, K., Seale, N. S., Kerins, C. A., \& McElvaney, R. (2008). The critical incident technique: A useful tool for conducting qualitative research. Journal of Dental Education, 72(3), 299-304.

Greeno, J. G., Collins, A. M., \& Resnick, L. B. (1996). Cognition and learning. In D. C. Berliner, \& R. C. Calfee (Eds.), Handbook of educational psychology (pp. 15-46). New York, N.Y.: Macmillan.

Himmelspach, J. (2009). A collaborative effort at diversification education. Grand Rapids Business Journal, $27(11), 3$.

Leenders, M. R., \& Erskine, J. A. (1989). Case research: The case writing process (3rd ed.). Ontario: University of Western Ontario.

Murtazina, K., \& Vendelinb, J. (2012). Student centred teaching approach for the informatics course. Paper presented at The 2nd International Conference on Future Computers in Education (ICFCE).

Wiley, D. A. (2002). The instructional use of learning objects. Bloomington: Agency for Instructional Technology. 